\section{J. Bucerius \\ J. F. Gummert \\ T. Walther \\ N. Doll \\ V. Falk \\ J. F. Onnasch \\ M. J. Barten \\ F. W. Mohr}

\title{
Impact of Diabetes Mellitus on Cardiac Surgery Outcome
}

\begin{abstract}
Background: Diabetes mellitus is an established independent risk factor related to significant morbidity and mortality after cardiac surgical procedures. Methods: Data on 16,184 patients undergoing cardiac surgery with and without cardiopulmonary bypass between April 1996 and August 2001 were prospectively evaluated. Diabetes mellitus as a patient related risk factor was subjected to univariate analysis to identify potential associations to 28 intra- and postoperative outcome variables. Outcome variables having a significant association with diabetes mellitus $(p<0.05)$ were then subjected to a stepwise logistic regression model to identify the influence of diabetes mellitus as compared to additional 30 different patient related risk factors and treatment variables. Diabetes mellitus was defined as glucose intolerance treated either dietary, with oral hypoglycemics or with insulin. Results: Overall prevalence of diabetes mellitus was
\end{abstract}

$33.3 \%$. Compared to non-diabetic patients the group with diabetes mellitus was older $(\mathrm{p}<0.0001)$ and had a significantly lower ejection fraction $(\mathrm{p}<0.0001) .15$ outcome variables having a significant association with diabetes mellitus were identified. Furthermore, diabetes mellitus could be identified as an independent predictor for 7 postoperative outcome variables (prolonged ICU-stay, sternal instability and/or infection, sternal revision and refixation respiratory insufficiency, postoperative delirium, perioperative stroke, renal dysfunction, postoperative reintubation). Conclusion: Diabetes mellitus is a significant independent predictor for several postoperative outcome variables after cardiac surgery associated with higher postoperative morbidity and prolonged hospital stay.

\section{Key words}

Diabetes mellitus · perioperative morbidity · cardiac surgery · beating heart surgery

\section{Introduction}

During the past years an increasing number of cardiac surgical procedures is performed on older patients having a considerable risk profile [1]. Despite this due to refinements in anesthesia and new surgical techniques (beating heart revascularization, small
ECC circuits) surgery has become a safe treatment option associated with a low morbidity and mortality for all patients.

Diabetes mellitus is an important risk factor for coronary artery disease, showing a more extensive and accelerated course $[2,3]$. Due to the poor quality of target vessels as well as their consider-

\section{Institution \\ Department of Cardiac Surgery, Heart Center, University of Leipzig, Leipzig, Germany}

Dedication

Presented at the $31^{\text {st }}$ Annual Meeting of the German Society for Thoracic and Cardiovascular Surgery, Leipzig, Germany; February 16-20, 2002

Correspondence

M.D. Jan Bucerius · University of Leipzig, Heart Center, Department of Cardiac Surgery · Strümpellstraße 39 . 04289 Leipzig · Germany · Phone: ++49/341/865-1421 · Fax: ++49/341/865-1452 . E-mail: bucerj@medizin.uni-leipzig.de

Received: July 1, 2002 
able co-morbidity, diabetic patients are considered poor candidates for coronary artery bypass grafting (CABG) and even worse for interventional techniques. The reported prevalence of diabetes among patients undergoing CABG varies from $7 \%$ to $20 \%$ $[4,5]$. Studies comparing CABG and percutaneous transluminal coronary angioplasty (PTCA) as treatment options in diabetic patients with coronary artery disease have been conflicting and are discussed critically [6,7]. Most past studies focused on mortality and long-term outcome following CABG surgery in diabetics. There is little in the way of data specifically analyzing perioperative morbidity in relation to diabetes and different surgical procedures are available [8-10].

Thus, aim of this study was to delineate the prevalence and the impact of diabetes on perioperative outcome of different cardiac surgical procedures.

\section{Material and Methods}

\section{Study population}

A total of 16,184 consecutive adult patients undergoing cardiac surgery between April 1996 and August 2001 were prospectively evaluated using an online database (Medwork ${ }^{\mathrm{TM}}$ database software, Lenz + Partner GmbH; Germany) [11]. Patients received standard CABG $(n=8917)$ or CABG on the beating heart $(n=1842)$ through either through a median sternotomy (OPCAB, $n=765$ ) or a left lateral minithoracotomy (MIDCAB, $n=1077$ ), mitral valve repair or replacement (MVS, $n=708$ ), aortic valve surgery (AVS, $n=1830$ ), double valve surgery (DVS, $n=381$ ) or combined procedures (COMB, $\mathrm{n}=2506$ ).

Patient characteristics are shown on Table 1 . The average age was $64.8 \pm 10.4$ years; $32.5 \%$ of patients were older than $70,3.6 \%$ were older than 80 in study population. Most patients were male $(72.2 \%)$

Table 1 Preoperative patient characteristics for the different surgical groups

\begin{tabular}{|lrlrll|}
\hline & \multicolumn{1}{c}{$\boldsymbol{n}$} & $\begin{array}{l}\text { age } \\
\text { (years) }\end{array}$ & $\begin{array}{l}\text { gender } \\
\text { male (\%) }\end{array}$ & $\begin{array}{l}\text { NYHA } \geq 3 \\
\text { (\%) }\end{array}$ & $\begin{array}{l}\text { LVEF } \\
\text { (\%) }\end{array}$ \\
\hline total & 16184 & $64.8 \pm 10.4$ & $11522(71.2 \%)$ & 77.7 & $52.0 \pm 22.0$ \\
\hline CABG & 8917 & $65.4 \pm 9.2$ & $6887(77.2 \%)$ & 79.9 & $53.0 \pm 20.6$ \\
\hline B. H. & 1842 & $63.1 \pm 10.6$ & $1402(76.1 \%)$ & 71.4 & $55.9 \pm 20.7$ \\
- OPCAB & 765 & $64.4 \pm 10.5$ & $613(80.1 \%)$ & 74.5 & $54.4 \pm 20.2$ \\
- MIDCAB & 1077 & $62.2 \pm 10.6$ & $789(73.3 \%)$ & 69.3 & $57.0 \pm 21.1$ \\
\hline MVS & 708 & $59.7 \pm 12.6$ & $333(47.0 \%)$ & 74.2 & $50.3 \pm 27.4$ \\
\hline AVS & 1830 & $61.5 \pm 13.7$ & $1127(61.6 \%)$ & 68.5 & $50.2 \pm 26.1$ \\
\hline DVS & 381 & $63.7 \pm 12.9$ & $171(44.9 \%)$ & 86.4 & $47.4 \pm 25.1$ \\
\hline COMB & 2506 & $68.3 \pm 8.8$ & $1602(63.9 \%)$ & 80.8 & $47.8 \pm 21.5$ \\
\hline
\end{tabular}

$C A B G$, coronary artery bypass grafting; Beating heart, OPCAB and MIDCAB approaches; OPCAB, off-Pump coronary bypass grafting; MIDCAB, minimally invasive direct coronary artery bypass grafting; MVS, mitral valve surgery; AVS, aortic valve surgery; DVS, double valve surgery; COMB, combined approaches CABG and valve or aortic surgery; LVEF, left ventricular ejection fraction

\section{Definition of diabetes mellitus}

Diabetes mellitus was defined as preoperative glucose intolerance treated by diet only, using oral hypoglycemics, or with insulin in order to determine the impact of this systemic disease regardless of its severity and treatment. Perioperative treatment of high glucose levels in patients with diabetic disease was carried out by subcutaneous or intravenous application of insulin during the ICU stay and establishment of preoperative treatment either by diet, with oral hypoglycemics or with insulin on the normal ward.

\section{Data collection}

All potential preoperative risk factors including diabetes mellitus for perioperative morbidity and mortality rate included in this analysis are listed in Table $\mathbf{2}$. Outcome variables indicating perioperative morbidity were evaluated for a possible association with preoperative diabetic disease and are shown in Table 3. ICU stay was defined as intensive care treatment, either in the intensive care unit or in the intermediate care unit without mechanical ventilation but still requiring close monitoring of cardiac function. Perioperative stroke was defined according to the Guidelines for reporting morbidity and mortality after cardiac valvular operations (Edmunds et al., 1996) as any new temporary or permanent, focal or global neurological deficit. A transient ischemic attack (TIA) was defined as a fully reversible neurological event lasting less than 24 hours. A prolonged reversible ischemic neurological deficit (PRIND) was defined as a fully re-

Table 2 Preoperative patient- and treatment variables subjected to univariate analysis with 28 perioperative outcome variables

\begin{tabular}{|ll}
\hline age $\geq 60<70$ years & preoperative cardiogenic shock \\
\hline age $\geq 70<80$ years & NYHA $\geq 3$ \\
\hline age $\geq 80$ years & $C C S \geq 3$ \\
\hline use of CPB & preoperative myocardial infarction \\
\hline OPCAB & LVEF $\leq 30 \%$ \\
\hline MIDCAB & history of peripheral vascular disease \\
\hline valve surgery & sex (male) \\
\hline combined approaches & history of renal disease \\
\hline double valve surgery & dialysis dependent renal \\
\hline $\begin{array}{l}\text { CABG } \\
\text { aortic valve + ascending aortic }\end{array}$ & preoperative atrial fibrillation \\
\hline surgery & \\
\hline aortic valve surgery & \\
\hline mitral valve surgery & \\
\hline prior cardiac surgery & \\
\hline diabetes mellitus & \\
\hline hyperlipidemia & \\
\hline arterial hypertension & \\
\hline history of pulmonary disease & \\
\hline history of cerebrovascular disease & \\
\hline history of embolism & \\
\hline preoperative infection & \\
\hline
\end{tabular}

$\mathrm{CPB}$, cardiopulmonary bypass; $\mathrm{CABG}$, coronary artery bypass grafting; Beating heart, OPCAB and MIDCAB approaches; OPCAB, off-pump coronary bypass grafting; MIDCAB, minimally invasive direct coronary artery bypass grafting; NYHA, New York Heart Association heart failure classification; CCS, Canadian Cardiovascular Society angina classification 
versible neurological deficit lasting between 24 and 3 weeks. Stroke was defined as permanent neurological event lasting for more than three weeks or causing death [12]. Postoperative delirium was defined in accordance with the American Psychiatric Association's guidelines [13]. Postoperative renal dysfunction was defined as increased serum creatinine and urea levels requiring medical treatment with diuretics. Postoperative hemofiltration was defined as any postoperative renal failure requiring first-time hemofiltration and/or dialysis during the postoperative stay. Postoperative atrial fibrillation was defined as any newly developed refractory atrial fibrillation lasting until discharge from the hospital. Postoperative infection was defined as any kind of infectious disease during postoperative stay on the ICU requiring antibiotic therapy. Rethoracotomy was defined as chest reopening due to bleeding, whereas reoperation with CPB comprised any secondary surgical intervention on the heart requiring cardiopulmonary bypass for coronary bypass revision or refixation of valve prosthesis. Preoperative infection comprised all different causes of infection, but mainly patients with a history of endocarditis.

\section{Statistical analysis}

Continuous variables are expressed as mean \pm standard deviation with categorical data as proportions. For continuous variables comparisons between patients with and without diabetes mellitus carried out using the student's t-test. Categorical variables were compared using $\chi^{2}$ analysis. Groups of patients related to different surgical procedures were compared by analysis of variance (ANOVA) with the appropriate correction for multiple comparisons. Univariate analysis of risk factors was performed calculating odds ratios (OR) with $95 \%$ confidence intervals. Diabetes mellitus as well as 30 additional patient- and treatmentrelated variables were evaluated regarding their possible association to 28 intra- and postoperative outcome variables. All pvalues were two-tailed. Preoperative patient- or treatment-related risk factors showing a significant association with one outcome variable ( $p$-value less than 0.05 ) were consecutively subjected to a multivariate logistic regression model. Thus, the independent impact of diabetes mellitus in comparison to other significant variables on perioperative outcome was assessed. A stepwise procedure (backward Wald) was used. A p-value less than 0.05 was used to enter and eliminate variables. All statistical analyses were performed using the SPSS statistical package version 9.0 (SPSS Corp, Birmingham, AL; USA).

\section{Results}

There were significant differences in preoperative patient characteristics (Table 1). These were as follows: Patients in the CABG group were significantly older compared to MIDCAB, MVS, DVS, and AVS patient groups $(\mathrm{p}<0.05)$. Within the beating-heart group, OPCAB patients were significantly older than patients in the MIDCAB group ( $=0.001$ ). Patients in the MVS group were significantly younger compared to all other groups $(p<0.05)$, and patients in the AVS group were significantly younger as compared to the OPCAB group $(\mathrm{p}<0.0001)$ and the DVS group $(p=0.002)$. Patients in the COMB group had a significantly higher age as compared to all other groups ( $\mathrm{p}<0.0001$ between COMB and all other groups).
Table 3 Perioperative outcome variables analyzed by univariate analysis (factors that had a statistically significant asociation with diabetes mellitus are printed in bold)

\begin{tabular}{|c|c|}
\hline & $p$ \\
\hline \multicolumn{2}{|l|}{ intraoperative variables } \\
\hline $\begin{array}{l}\text { - duration of surgery } \geq \mathbf{3} \mathbf{~ h r} \\
\text { - total CPB time } \geq \mathbf{2} \mathbf{~ h r} \\
\text { - ischemic time } \geq \mathbf{1 ~ h r} \\
\text { - intraoperative blood loss } \geq \mathbf{5 0 0} \mathbf{~} \mathbf{~ l} \\
\text { - intraoperative hemofiltration } \\
\text { - intraoperative RBC-transfusion } \geq 1000 \mathbf{~ m l} \\
\text { - intraoperative low output } \\
\text { - intraoperative IABP } \\
\text { - urgent operation }\end{array}$ & $\begin{aligned} & 0.013 \\
& 0.029 \\
< & 0.0001 \\
< & 0.0001 \\
& 0.523 \\
& 0.19 \\
& 0.458 \\
& 0.228 \\
& 0.89\end{aligned}$ \\
\hline \multicolumn{2}{|l|}{ perioperative variables } \\
\hline $\begin{array}{l}\text { - perioperative } \mathbf{R B C} \text { - transfusion } \geq \mathbf{2 0 0 0} \mathbf{~ m l} \\
\text { - postoperative blood loss } \geq 500 \mathrm{ml}\end{array}$ & $\begin{array}{c}<0.0001 \\
0.929\end{array}$ \\
\hline \multicolumn{2}{|l|}{ postoperative variables } \\
\hline $\begin{array}{l}\text { - delirium } \\
\text { - stroke } \\
\text { - dysrhythmia } \\
\text { - low cardiac output } \\
\text { - renal insufficiency } \\
\text { - sternal infection and/or instability } \\
\text { - prolonged duration of intubation ( } \geq \mathbf{2} \text { days) } \\
\text { - respiratory insufficiency } \\
\text { - postoperative reintubation } \\
\text { - prolonged ICU-stay ( } \mathbf{5} \text { days) } \\
\text { - postoperative myocardial infarction } \\
\text { - rethoracotomy } \\
\text { - reoperation with CPB } \\
\text { - postoperative hemofiltration } \\
\text { - postoperative atrial fibrillation } \\
\text { - postoperative infection } \\
\text { - } 30 \text { postoperative day mortality }\end{array}$ & $\begin{aligned}< & 0.0001 \\
< & 0.0001 \\
< & 0.0001 \\
< & 0.0001 \\
< & 0.0001 \\
< & 0.0001 \\
& 0.005 \\
< & 0.0001 \\
< & 0.0001 \\
< & 0.0001 \\
& 0.167 \\
& 0.577 \\
& 0.159 \\
& 0.287 \\
& 1.0 \\
& 0.679 \\
& 1.0\end{aligned}$ \\
\hline
\end{tabular}

IABP, intra-aortic ballon pump; RBC, red blood cells; CPB, cardiopulmonary bypass; ICU, intensive care unit

Patients in the coronary artery bypass groups (CABG, OPCAB, MIDCAB) had a significantly higher left ventricular ejection fraction (LVEF) than all other groups $(p<0.05)$. Prevalence of impaired NYHA-classification $(\geq 3)$ was highest in the DVS group, reaching statistically significant differences as compared to all other groups ( $p<0.0001$ vs. all other groups) with the exception of the COMB group ( $p=n s$ ). Additionally, prevalence in the CABG group was significantly higher in comparison to all other groups $(p<0.05)$ except of the COMB and the DVS group $(p=n s)$. Prevalence of NYHA-classification $\geq 3$ in the COMB group was significantly higher as compared to all other groups $(p<0.05)$ with the exception of the DVS and the CABG group $(p=n s)$.

The overall prevalence of diabetes mellitus was 33.3\%. Prevalence varied among the different surgical procedures (Fig.1). The highest prevalence was found within the CABG (37.5\%) and the COMB group (37.4\%) reaching statistically significant differences compared to all other groups $(p<0.0001)$ with the exception of the OPCAB group ( $p=0.1$ vs. CABG and $p=0.24$ vs. COMB, respectively). Lowest prevalence could be observed in both valve groups - MVS: $17.1 \%$ ( $p<0.0001$ vs. all other groups except DVS; $\mathrm{p}=0.03$ and AVS; $\mathrm{p}=\mathrm{ns}) ;$ AVS: $19.4 \%(\mathrm{p}<0.0001$ vs. all other groups except DVS and MVS; $p=n s$ ). 
Prevalence (\%)

Prevalence (\%)
Fig. 1 Prevalence of diabetes mellitus according to the type of cardiac surgery.
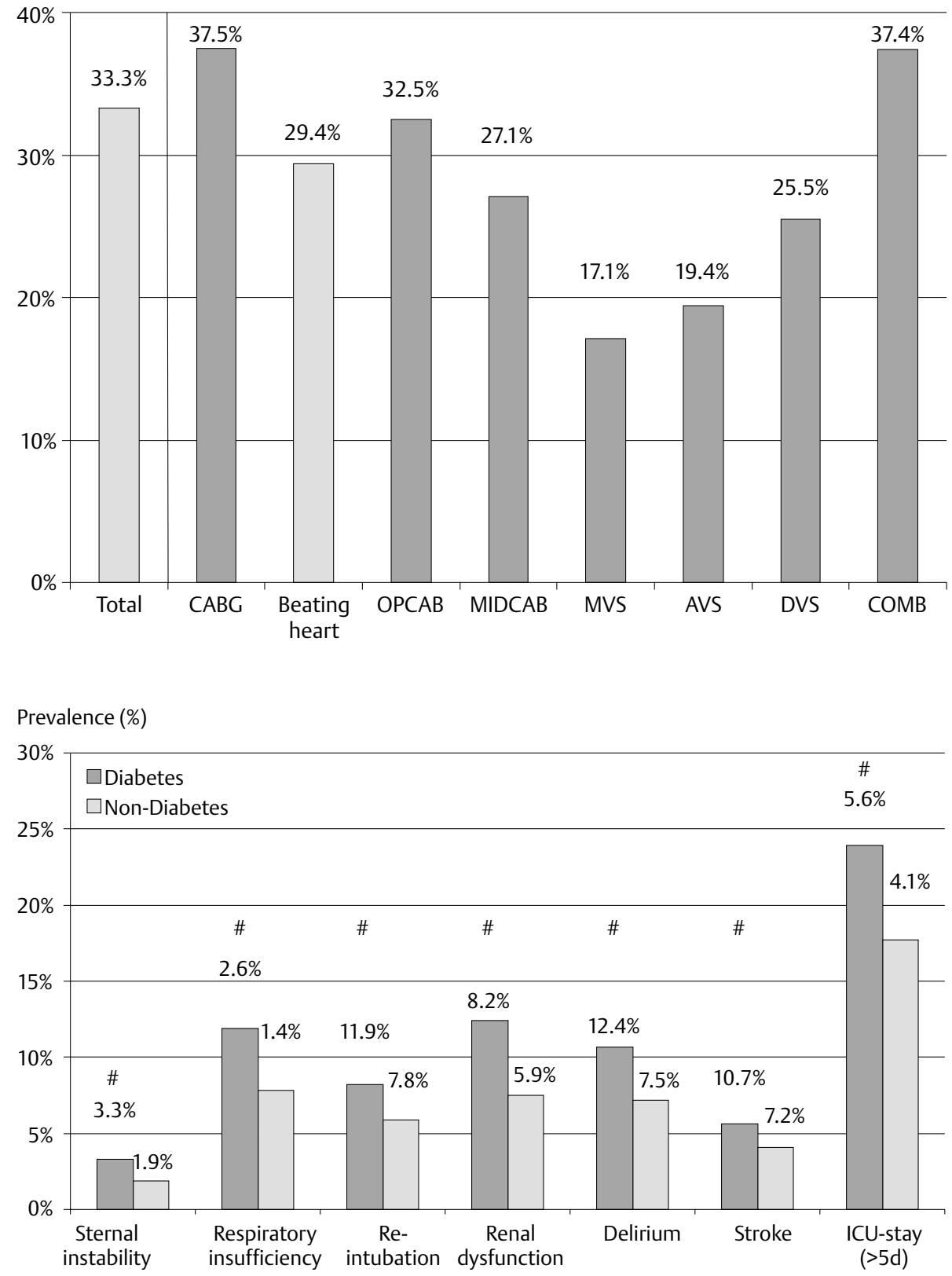

Fig. 2 Prevalence of perioperative outcome variables associated with diabetes mellitus in patients with and without diabetic disease.
Diabetics were significantly older ( 66.4 years \pm 8.7 vs. 64.1 years $\pm 11.1 ; \mathrm{p}<0.0001)$ and had a significantly lower LVEF $(50.9 \% \pm 20.7$ vs. $52.5 \% \pm 22.6$; $p<0.0001)$ as patients without diabetes for all groups, respectively. Furthermore, diabetic patients suffered significantly more often from impaired preoperative NYHA-classification (76.2\% vs. $80.6 \%$; p < 0.0001 ). $67.3 \%$ of the diabetic patients were male.

Table 2 shows variables with significant impact on outcome. Table $\mathbf{3}$ identifies factors with a statistically significant association with diabetes mellitus (printed in bold). Diabetes mellitus was identified as an independent risk factor for eight outcome variables as shown in Table 4.

Prevalence of outcome variables significantly associated with preoperative diabetic disease; statistically significant differences between diabetic and non-diabetic patients are shown in Fig. 2. Diabetics had a longer ICU stay ( $4.8 \pm 7.7$ days vs. $3.9 \pm 6.5$ days; $\mathrm{p}<0.0001)$ and hospital stay $(12.5 \pm 10.9$ vs. $7.9 \pm 357.4$ days; $\mathrm{p}=\mathrm{ns}$ ). In-hospital mortality was $5.2 \%$ (diabetics) versus $4.3 \%$ $(\mathrm{p}=0.01)$.

\section{Discussion}

Overall prevalence of diabetes mellitus in this large study cohort including more than 16,000 adult patients was $33.3 \%$ while varying among different diagnoses. Prevalence was highest in all CABG groups with or without cardiopulmonary bypass and in the COMB group comprising patients undergoing CABG and valve surgery. As diabetes mellitus one important independent risk factor for coronary artery disease, this was not an unexpect- 
Table 4 Perioperative outcome variables significantly associated with diabetes mellitus

\begin{tabular}{lllr}
\hline outcome-variables & odds-ratio & $\begin{array}{l}\text { 95\% confi- } \\
\text { dence } \\
\text { intervall }\end{array}$ & p value \\
& diabetes mel litus \\
\hline - sternal instability and/or infection & 1.35 & $1.02-1.78$ & 0.03 \\
\hline - respiratory insufficiency & 1.37 & $1.22-1.54$ & $<0.0001$ \\
- postoperative reintubation & 1.27 & $1.11-1.45$ & 0.0004 \\
\hline - renal insufficiency & 1.43 & $1.26-1.61$ & $<0.0001$ \\
\hline - postoperative delirium & 1.38 & $1.22-1.56$ & $<0.0001$ \\
\hline - perioperative stroke & 1.25 & $1.06-1.48$ & 0.007 \\
\hline - prolonged ICU-stay ( $\geq 5$ days) & 1.27 & $1.16-1.39$ & $<0.0001$ \\
\hline
\end{tabular}

variable analyzed by multivariate logistic regression analysis

ed finding [14]. However, prevalence in the MIDCAB group was lowest within patients undergoing CABG procedures - only slightly higher than the DVS group. Diabetics have been found to be significantly older and to have a significantly lower LVEF both of these variables being co-morbidities related to an impaired postoperative outcome as reported by some series $[8,15]$.

This series revealed diabetes mellitus as an independent risk factor for several perioperative outcome variables. Recent studies have associated diabetes with stroke and postoperative delirium $[8,16,17]$. Similarly, we found a significantly higher incidence of both these neurological complications in diabetics as shown on Fig. 2. As diabetes mellitus is one of the well-known risk factors of artherosclerotic disease, diabetics are at an increased risk of cerebral embolization due to atherosclerosis [14]. In addition, since atherosclerotic disease is a systemic disorder in most cases, involvement of the cerebral and carotid arteries leading to impaired cerebral blood flow is not uncommon. Furthermore, autoregulation of cerebral blood flow seems to be impaired by diabetes mellitus, a finding which may even be exacerbated intraoperatively during СРB [18]. However, although an increased morbidity has been documented for diabetics after CABG by Fietsam and associates, that study series could not show and higher prevalence of stroke among these patients [5]. The systemic character of diabetic disease can be emphasized by the significant association between diabetes mellitus and postoperative renal insufficiency as found in a series by Morricone and associates as well as in this series (OR: 1.43) [17]. As mentioned above, atherosclerosis is one of the most reported diseases caused by diabetes mellitus, and may affect several organic systems. As such, renal insufficiency due to atherosclerotic alterations of the renal arteries is not surprising.

As expected and reported by other series, diabetes mellitus was an independent predictor for sternal instability associated with or without infection (OR: 1.35) [19]. Meticulous control of perioperative serum glucose levels should be beneficial in reducing the risk of sternal infection and, subsequently, surgical revision in diabetic patients as reported by Furnary and associates [19]. In this series, postoperative high glucose levels were treated by either single or continuous intravenous or subcutaneous insulin application.
Postoperative respiratory insufficiency (OR: 1.37) and consecutive postoperative reintubation (OR: 1.27) both significantly associated with diabetes mellitus in this series seem to be indicators for the systemic impact of diabetic disease. Most of the reported postoperative complications associated with diabetic disease in this series could be also associated with impaired respiratory function. As such, the impact of diabetes mellitus on both of these outcome variables is most likely indirect, in contrast to the direct influence of diabetes mellitus on respiratory function. This can help explain the prolonged ICU stay, which is in accordance with the current literature [17].

Diabetes mellitus has been associated with a higher perioperative morbidity as well as decreased survival after coronary artery bypass grafting $[2,3,9]$. These findings were confirmed by our study. Furthermore, in-hospital mortality was significantly higher in diabetics.

With regard to the severity of diabetic disease, neither degree of glucose intolerance nor mode of medical therapy seem to be major determinants in early or late survival [3]. Furthermore, Magee and associates found similar perioperative results after narrowing the entire diabetic patient group to only treated diabetic patients, either with oral medication or insulin. Narrowing the analysis even more to diabetic patients treated with insulin also led to similar results to the analysis of the whole diabetic subgroup [10]. Thourani and associates found no significant differences with regard to postoperative myocardial infarction, stroke, death during hospitalization, or overall length of hospital stay between insulin-treated diabetic patients undergoing CABG compared to diabetic patients not treated with insulin [8].

In order to determine the systemic impact of diabetes mellitus, we looked at all patients with diabetes mellitus together regardless of severity or preoperative treatment. Further large cohort studies, investigating the impact of insulin-treatment on perioperative outcome in diabetic patients have to be undertaken.

In conclusion, diabetes mellitus is a significant preoperative predictor for several complications after cardiac surgical procedures. Additionally, in times of limited health care resources and increasing importance of economic aspects, patients with diabetic disease undergoing cardiac surgical interventions should receive special attention either in the pre- as well as in the perioperative time period. This may lead to an improved perioperative outcome in diabetic patients, and therefore to reduced postoperative intensive care treatment costs.

\section{References}

${ }^{1}$ Kalmár P, Irrgang E. Cardiac Surgery in Germany during 2000. A Report by the German Society for Thoracic and Cardiovascular Surgery. Thorac Cardiov Surg 2001; 49: XXXIII - XXXVIII

2 Morris JJ, Smith LR, Jones RH, et al. Influence of diabetic and mammary artery grafting on survival after coronary artery bypass. Circulation 1991; 84 (Suppl III): III-275 - III-284

${ }^{3}$ Salmon NW, Page US, Okies JE, Stephens J, Krause AH, Bigelow JC. Diabetes mellitus and coronary artery bypass. Short term risks and long term prognosis. J Thorac Cardiovasc Surg 1983; 85: 264-271 
${ }^{4}$ Herlitz J, Karlson BW, Wognsen GB, et al. Mortality and morbidity in diabetic and nondiabetic patients during a 2-year period after coronary artery bypass grafting. Diabetes Care 1996; 19: 698-703

${ }^{5}$ Gum PA, O'Keefe JH Jr, Borkon AM, et al. Bypass surgery versus coronary angioplasty for revascularization of treated diabetic patients. $\mathrm{Cir}-$ culation 1997; 96 (Suppl II): II-7 - II-10

${ }^{6}$ The Bypass Angioplasty Revascularization Investigation (BARI) Investigators. Comparison of coronary bypass surgery with angioplasty in patients with multivessel disease. N Engl J Med 1996; 335: 217-225

7 Thourani VH, Weintraub WS, Stein B, et al. Influence of diabetes mellitus on early and late outcome after coronary artery bypass grafting. Ann Thorac Surg 1999; 67: 1045 - 1052

${ }^{8}$ Cohen Y, Raz I, Merin G, Mozes B, for the Israeli Coronary Artery Bypass (ISCAB) Study Consortium. Comparison of factors associated with 30-day mortality after coronary artery bypass grafting in patients with versus without diabetes mellitus. Am J Cardiol 1998; 81: 7-11

${ }^{9}$ Magee MJ, Dewey TM, Acuff T, et al. Influence of diabetes on mortality and morbidity: Off-pump coronary bypass grafting versus coronary artery bypass grafting with cardiopulmonary bypass. Ann Thorac Surg 2001; 72: 776-781

${ }^{10}$ Gummert JF, Kluge M, Reißmann EM, et al. Einführung eines komplexen medizinischen Dokumentationssystems am Herzzentrum Leipzig. In: Krian A, Scheld HH, editors. Dokumentationsverfahren in der Herzchirurgie III. Darmstadt: Steinkopff, 1998: 99-103

${ }^{11}$ Edmunds LH Jr, Clark RE, Cohn LE, Grunkemeier GL, Miller DC, Weisel RD. Guidelines for reporting morbidity and mortality after cardiac valvular operations. J Thorac Cardiovasc Surg 1996; 112: 708 - 711
${ }^{12}$ American Psychiatric Association. Diagnostic and Statistical Manual of Mental Disorders, 3rd ed revised. Washington, DC, American Psychiatric Association, 1987

${ }^{13}$ Kannel WB, McGee DL. Diabetes and cardiovascular risk factors: the Framingham Study. Circulation 1979; 59: 8-13

${ }^{14}$ Petros AJ, Marshall JC, van Saene HKF. Should morbidity replace mortality as an end-point for clinical trials in intensive care? Lancet 1995; 345: $369-371$

${ }^{15}$ Roach GW, Kanchuger M, Mora Mangano C, et al. Adverse cerebral outcomes after coronary bypass surgery. Multicenter study of perioperative ischemia research group and the ischemia research and education foundation investigators. N Engl J Med 1996; 335: 1857-1863

${ }^{16}$ Morricone L, Ranucci M, Denti S, et al. Diabetes and complications after cardiac surgery: comparison with a non-diabetic population. Acta Diabetol 1999; $36(1-2)$ : $77-84$

${ }^{17}$ Bentsen N, Lausen B, Lassen NA. Chronically impaired autoregulation of cerebral blood flow in long-term diabetics. Stroke 1975; 6: $497-$ 502

${ }^{18}$ Gummert JF, Barten MJ, Hans C, et al. Mediastinitis and cardiac surgery - An updated risk factor analysis in 10,373 consecutive adult patients. Thorac Cardiovasc Surg 2002; 41: 1 -5

${ }^{19}$ Furnary AP, Zerr KJ, Grunkemeier GL, Starr A. Continuous intravenous insulin infusion reduces the incidence of deep sternal wound infection in diabetic patients after cardiac surgical procedures. Ann Thorac Surg 1999; 67 (2): $352-360$ 